\title{
Adsorption isotherms and kinetics for dibenzothiophene on activated carbon and carbon nanotube doped with nickel oxide nanoparticles
}

\author{
MAZEN K NAZAL ${ }^{1,2}$, GHASSAN A OWEIMREEN ${ }^{1}$, MAZEN KHALED ${ }^{1, *}$, MUATAZ A ATIEH ${ }^{3}$, \\ ISAM H ALJUNDI ${ }^{4}$ and ABDALLA M ABULKIBASH ${ }^{1}$ \\ ${ }^{1}$ Chemistry Department, King Fahd University of Petroleum \& Minerals (KFUPM), Dhahran 31261, Saudi Arabia \\ ${ }^{2}$ Center of Environmental \& Water at Research Institute, King Fahd University of Petroleum \\ \& Minerals (KFUPM), Dhahran 31261, Saudi Arabia \\ ${ }^{3}$ Qatar Environment and Energy Research Institute, Qatar Foundation, PO Box 5825, Doha, Qatar \\ ${ }^{4}$ Chemical Engineering Department, King Fahd University of Petroleum \& Minerals (KFUPM), Dhahran 31261, \\ Saudi Arabia
}

MS received 30 July 2015; accepted 21 October 2015

\begin{abstract}
Activated carbon (AC) and multiwall carbon nanotubes (CNT) doped with 1, 5 and $10 \% \mathrm{Ni}$ in the form of nickel oxide nanoparticles were prepared using the wetness impregnation method. These percentages were denoted by the endings NI1, NI5 and NI10 in the notations ACNI1, ACNI5, ACNI10 and CNTNI1, CNTNI5, CNTNIL10, respectively. The physicochemical properties for these adsorbents were characterized using $\mathbf{N}_{2}$ adsorption-desorption surface area analyzer, thermal gravimetric analysis (TGA), scanning electron microscopy, energy-dispersive X-ray spectroscopy, field-emission transmission electron microscopy, X-ray diffraction and X-ray photoelectron spectrometre. Adsorption isotherms were obtained and desulphurization kinetics were carried out on solutions of dibenzothiophene (DBT) and thiophene in a model fuel. The efficiencies of DBT and thiophene removal were reported. The adsorption isotherms fitted the Langmuir and Freundlich models. The highest adsorption capacity for DBT was $74 \pm 5 \mathrm{mg} \mathrm{g}^{-1}$ on ACNI5; the maximum adsorption capacities of the other adsorbents followed the trend ACNI1 > ACNI10 > AC > CNTNI5 > CNTNI1 > CNTNI10 > CNT. The adsorption rates for DBT and thiophene followed pseudo-second-order kinetics. The selective removal by these adsorbents of DBT relative to thiophene and naphthalene was evaluated. The adsorbents' reusability and the effect of the percentage of aromatic compounds on their adsorption capacity were also reported.
\end{abstract}

Keywords. Model fuel; thiophene; selectivity; adsorptive removal; reusability.

\section{Introduction}

The presence of refractory thiophenic compounds in fuel leads to very serious environmental and health problems. The main reason for acid rain is $\mathrm{SO}_{x}$ emission from fuel combustion that containing these compounds. In refinery industries, these sulphur compounds cause a poisoning of the catalysts and accelerate the pipelines' corrosion [1]. Consequently, the removal of these thiophenic compounds (i.e., benzothiophene, dibenzothiophene (DBT), and its derivatives) from gasoline and diesel is highly important. In 2009 the European commission passed a regulation in decreasing the maximum sulphur content in diesel fuel from 2000 to $10 \mathrm{ppmw}$ [2]. In 2006, the U.S. Environmental Protection Agency (USEPA), restricted the sulphur level in highway diesel and in gasoline to 15 and 30 ppmw, respectively [3].

The conventional hydrodesulphurization (HDS) technique removes most of the sulphur compounds (thiols and sulphides) but not the refractory thiophenic compounds such as benzothiophene, dibenzothiophene and their derivatives

\footnotetext{
*Author for correspondence (mkhaled@kfupm.edu.sa)
}

[4]. The Z-Sorb process, which is based on catalytic hydrodesulphurization, removes sulphur compounds efficiently, but cannot remove alkylated thiophenic compounds from gasoline and diesel fuel [5]. To comply with the restrictive specifications and regulations on transportation fuel, hydrodesulphurization requires high temperature, high pressure and large amount of hydrogen which increase the cost of fuels dramatically [6]. One way to comply with the new regulations and produce near zero sulphur fuel is to use different removal approaches or improve the current desulphurization methods.

Many desulphurization processes such as oxidative desulphurization [7-10], photooxidative desulphurization [11,12] and adsorptive desulphurization [13-31] have been investigated. Adsorptive desulphurization is a promising technique. It is cost effective, and as a complementary technique removes sulphur compounds to near zero values, is easily adaptable to the refining industries and uses absorbents that can be re-generated $[4,22]$. Several researchers have explored the unmodified carbon-based materials $[18,19,21]$ or carbonbased materials modified with acidic functional groups or transition metals $[13,15-17,20,23-25,28]$ for DBT removal. 
Yang's research group [13,15,16] and Jing et al [23] found that doping of activated carbon (AC) and zeolites with transition metals (i.e., $\mathrm{Ag}, \mathrm{Ni}, \mathrm{Zn}, \mathrm{Cu}$ and $\mathrm{Pd}$ ) lead to significant enhancement in their adsorption capacity and selectivity for removal of sulphur compounds in commercial fuel at ambient temperature and pressure, which they attributed to $\pi$-complexation. They reported also that impregnation of carbon materials and zeolites with $\mathrm{Fe}$ decreased their adsorption capacity for sulphur compounds. More recently, Elham and co-workers [25] found that the doping of hydrogen-treated $\mathrm{AC}$ and $\mathrm{AC}$ fibre with metals oxide such as $\mathrm{NiO}, \mathrm{Cu}_{2} \mathrm{O}$ or $\mathrm{CuO}$ improved their adsorption capacity for thiophenic compounds in a model fuel. They also attributed this to specific interaction between thiophenic compounds and the $\mathrm{Ni}$ and $\mathrm{Cu}$ cationic species via $\pi$-complexation.

In the HDS process, carbon nanotube (CNT) modified with CoMoS removes DBT more efficiently than AC or alumina modified with CoMoS. This is attributable to its nano size and in turn, the higher ratio it achieves between the adsorbed DBT surface area and the catalysts total surface area [32], even though $\mathrm{AC}$ has a higher surface area and loading capacity. It is also likely that the curvature of the CNT places a strain on the adsorbed DBT, rendering it more reactive than on $\mathrm{AC}$.

The chemistry of adsorbents' surface is a crucial factor for DBT adsorption, whereas the acidic groups [33] and metals oxide such as $\mathrm{MgO}, \mathrm{ZnO}, \mathrm{Al}_{2} \mathrm{O}_{3}$ and $\mathrm{TiO}_{2}$ [34] on the surface of adsorbent play a major role in improving their surface and in turn enhancing adsorption of DBT from model fuel. This chemistry is attributed to Bronsted and Lewis acids of varying coordination [34]. Selectivity and activity of metal oxides are related to their acid-base properties which are a function with constituents, preparation method, composition and pre-treatment conditions [35]. The nickel transition metal belongs to the fourth period and tenth group in the periodic table and as a result it manifests better catalytic activity compared to most of other metals. In addition, the nickel oxide is easily prepared with moderate cost.

Hydrogen bonding between the associated hydroxyl groups on the adsorbent's surface with the lone electron pair on sulphur atom and/or electron cloud on aromatic rings in sulphur compounds structure can also play a significant role in the adsorption of sulphur compounds [36].

Thiophene and specifically DBT removal are important challenges faced by the refinery industry and complementary techniques are needed to continue providing low-sulphur fuels without increasing refining costs or energy demands. Therefore introducing an additional adsorption site such as low cost nickel oxide nanoparticles on the surface of promising adsorptive material such as CNT and AC which has distinct properties, is expected to improve the adsorption capability for sulphur compounds such as DBT (Lewis base), thereby providing a new adsorbent. This study investigates the adsorption capacity of CNT modified with different loadings of nickel oxide nanoparticles for the removal of DBT and thiophene from a model fuel. The selectivity of CNT and
AC for DBT were compared before and after doping CNT and $\mathrm{AC}$ with 5\% nickel oxide nanoparticles; the loading that gave the highest adsorption capacity. The reusability of the adsorbents and the effect of aromatic compounds on their adsorption capacity were also studied.

\section{Experimental}

\subsection{Materials}

Multi-wall CNTs (purity 95\%, outer diameter (OD) 10$20 \mathrm{~nm}$, length 10-30 $\mu \mathrm{m}$, and specific surface area (SSA) $200 \mathrm{~m}^{2} \mathrm{~g}^{-1}$ ), and coconut granular AC were purchased from Timesnano Company and Cenapro Chemical Corporation, Mandaue City, Philippine, respectively, and they were used as received. Analytical grade ethanol, dibenzothiophene (DBT) $>99 \%$, thiophene $>99 \%$, nickel nitrate hexahydrate $\left(\mathrm{Ni}\left(\mathrm{NO}_{3}\right)_{2} \cdot 6 \mathrm{H}_{2} \mathrm{O}\right), n$-hexane anhydrous HPLC grade $>99 \%$, and analytical grade $n$-heptane, benzene, toluene and xylene were purchased from Sigma-Aldrich. Naphthalene $>98 \%$ was purchased from Fluka.

\subsection{Adsorbents preparation and characterization}

$\mathrm{AC}$ and CNT adsorbents doped with 1, 5 and $10 \%$ nickel in the form of nickel oxide nanoparticles (NI) were prepared. These doped adsorbents are denoted by ACNI1, ACNI5, ACNI10 and CNTNI1, CNTNI5, CNTNI10, respectively. The procedure involved dissolving the appropriate mass of nickel nitrate hexahydrate in a $400 \mathrm{ml} 1 \%$ deionized water in ethanol, then adding the resulting solution slowly and with stirring to the appropriate mass of CNT or AC. The resulting solutions were kept under ultrasound vibrator for $2 \mathrm{~h}$. The resulting suspensions were dried in an oven at $70^{\circ} \mathrm{C}$ for $72 \mathrm{~h}$ and the produced powder was ground then calcinated at $300^{\circ} \mathrm{C}$ for $2 \mathrm{~h}$. The doped adsorbents were stored in tightly closed vials.

The prepared adsorbents in this study were characterized using thermogravimetric analysis (TGA) (TA Instrument Q Series Q600 SDT) to study their oxidation under atmospheric air. For each measurement, approximately a 10 $\mathrm{mg}$ sample was heated from room temperature to $800^{\circ} \mathrm{C}$ at a rate of $10^{\circ} \mathrm{C} \mathrm{min}{ }^{-1}$ under air with a flow rate of $100 \mathrm{ml}$ $\min ^{-1}$. The adsorbents texture and morphology were studied using scanning electron microscopy (SEM) (TESCAN LYRA3) coupled with energy-dispersive X-ray spectroscopy (EDX) Oxford detector model X-Max. JOEL-2100F field emission transmittance electron microscope (FE-TEM) was used for particle size measurement. The CNT doped with nickel oxide crystal structure was evaluated using an X-ray diffractometer instrument (Rigaku MiniFlexII Desktop) with a $\mathrm{CuK} \alpha$ source and $2 \theta$ angle in the range $10-100^{\circ}$ at a slow scan rate of $2 \theta \mathrm{min}^{-1}$. The oxidation state of nickel doped on the adsorbents surface was determined using X-ray photoelectron spectrometer (XPS) (Thermo scientific ESCALAB 250Xi). 


\subsection{Adsorbents' surface pH measurements}

About $0.2 \mathrm{~g}$ of well-dried adsorbent were suspended in $10 \mathrm{ml}$ distilled water then sonicated for $2 \mathrm{~h}$. The resulting suspension was filtered and the $\mathrm{pH}$ of the filtrate was measured using a $\mathrm{pH}$ meter (Thermo Scientific Cyber Scan $\mathrm{pH}$ 1500).

\subsection{Characterization of the adsorbents surface area and porosity}

The surface area and porosity of samples of the adsorbents were obtained using an automated gas sorption analyzer (Autosorb iQ Quantachrome USA) at relative pressures between 0.01 and 1.00 . The liquid nitrogen adsorptiondesorption isotherms were measured after degassing all the adsorbents at $200^{\circ} \mathrm{C}$ to a pressure of $6.5 \times 10^{-5}$ Torr. The Brunauer-Emmett-Teller (BET) method [37] was used to calculate the surface area (SA) while the micropore volume (V) and surface area were calculated from the $V-t$ method [38].

\subsection{Analytical method}

HPLC-UV (Agilent Technology 1260 Infinity series) system was used to determine the concentrations of thiophene, DBT and naphthalene before and after their adsorption from $n$-hexane as a model fuel. A $5 \mu$ sample was injected and the components were separated using a $20 \mathrm{~cm} \times 4.6 \mathrm{~mm}$ I.D. silica column and $n$-hexane as mobile phase at a flow rate $1.00 \mathrm{ml} \mathrm{min}^{-1}$. The thiophene was detected earlier (after around $3.5 \mathrm{~min}$ ) using a $235 \mathrm{~nm}$ wavelength while DBT and naphthalene were detected later using a $280 \mathrm{~nm}$ wavelength and were well separated. The total run time was within $5 \mathrm{~min}$. This wavelength switching was convenient to permit measurements of higher concentrations of DBT and naphthalene.

Standard solutions were used to prepare calibration curves with concentrations ranging from 2.5 to $250 \mathrm{mg}^{-1}$ for each of thiophene and DBT and from 10 to $1000 \mathrm{mg} \mathrm{l}^{-1}$ for naphthalene. Runs on standard ternary mixtures having the same concentration of these compounds and falling within their same concentrations ranges demonstrated their simultaneous linearity and that the analytes have no effect on each other.

\subsection{Adsorption experiments}

All the adsorption experiments were at $25.0^{\circ} \mathrm{C}$. To a $150 \mathrm{mg}$ sample of adsorbent a solution of thiophene or DBT in $n$-hexane was added and the system was agitated at $200 \mathrm{rpm}$ for $2 \mathrm{~h}$ then allowed to settle. The concentration of thiophene or DBT in the filtrate was measured using HPLC and the amount of adsorbed thiophene or DBT was calculated. The concentrations of thiophene or DBT used on each of the adsorbents AC, ACNI10, ACNI5, ACNI1, CNT, CNTNI10, CNTNI5 and CNTNI1 were 25, 50, 100, 125, 150, 200 and $250 \mathrm{mg} \mathrm{l}^{-1}$.
In each of the adsorption kinetics experiments $25 \mathrm{ml}$ of a solution containing $250 \mathrm{mg}$ of thiophene or BDT per litre of $n$-hexane was added to a $150 \mathrm{mg}$ sample of carbonaceous adsorbent modified with nickel oxide and the mixture was shaken for $10 \mathrm{~min}$. Using HPLC (see section 2.5) the residual concentration of thiophene or DBT was measured. This procedure was repeated for shaking time intervals of 20,30 , 40, 60, 120, 240 and $1560 \mathrm{~min}$.

The effect of adsorbent dose on the removal of thiophene or DBT from solutions containing $250 \mathrm{mg}$ of them per litre of $n$-hexane was studied by varying the adsorbent dose from 50 to $750 \mathrm{mg}$ and shaking the mixtures for $2 \mathrm{~h}$ at a speed of $200 \mathrm{rpm}$.

\subsection{Selectivity experiments}

Solutions of thiophene, naphthalene and DBT in $n$-hexane were studied. Thiophene was chosen to model small aromatic sulphur-containing compounds. Naphthalene was selected as a representative of polyaromatic hydrocarbons (PAH). Thiophene and naphthalene have structures similar to DBT and all three are present in diesel fuel. Seven adsorption measurements were carried out at $25^{\circ} \mathrm{C}$ and shaking speed of 200 rpm for $2 \mathrm{~h}$ using $150 \mathrm{mg}$ of adsorbent in $25 \mathrm{ml}$ of model fuel solutions of each of thiophene, DBT and naphthalene. In experiments 1-7 the concentrations of DBT or thiophene were $25,50,100,125,150,200$ and $250 \mathrm{mg}^{-1}$, respectively, and those of naphthalene were 100, 200, 400, 500, 600,800 and $1000 \mathrm{mg} \mathrm{l}^{-1}$, respectively. The concentrations of these three compounds were measured before and after the adsorption experiment.

\section{Results and discussion}

\subsection{Characterization of adsorbents}

3.1a TGA: The TGA for the parent carbon materials (AC and $\mathrm{CNT}$ ), the pre-calcined carbon materials doped with $10 \%$ $\mathrm{Ni}$ in the form of $\mathrm{Ni}\left(\mathrm{NO}_{3}\right)_{2} \cdot 6 \mathrm{H}_{2} \mathrm{O}$, and the doped calcined materials $(\mathrm{AC} \cdot \mathrm{NiO}$ and $\mathrm{CNT} \cdot \mathrm{NiO})$ are shown in figure 1 and the results are summarized in table 1.

3.1b Surface morphology and texture: Figure 2 shows the SEM images of AC and CNT before and after doping with $10 \%$ nickel oxide. Needle-like nickel oxide nanoparticles were observed on the surface of AC while spherical-shaped nanoparticles of nickel oxide were observed on the surface of CNT. Table 2 presents the elemental composition of the doped carbon adsorbents obtained from an EDX. It was found that $\mathrm{AC}$ has a higher oxygen content compared to CNT owing to availability of oxygenated functional groups on its surface. As a result of doping with nickel oxide the oxygen percentage in the adsorbents increased. Table 2 also shows that the weight percentages of nickel obtained from EDX are in good agreement with the experimentally expected values 

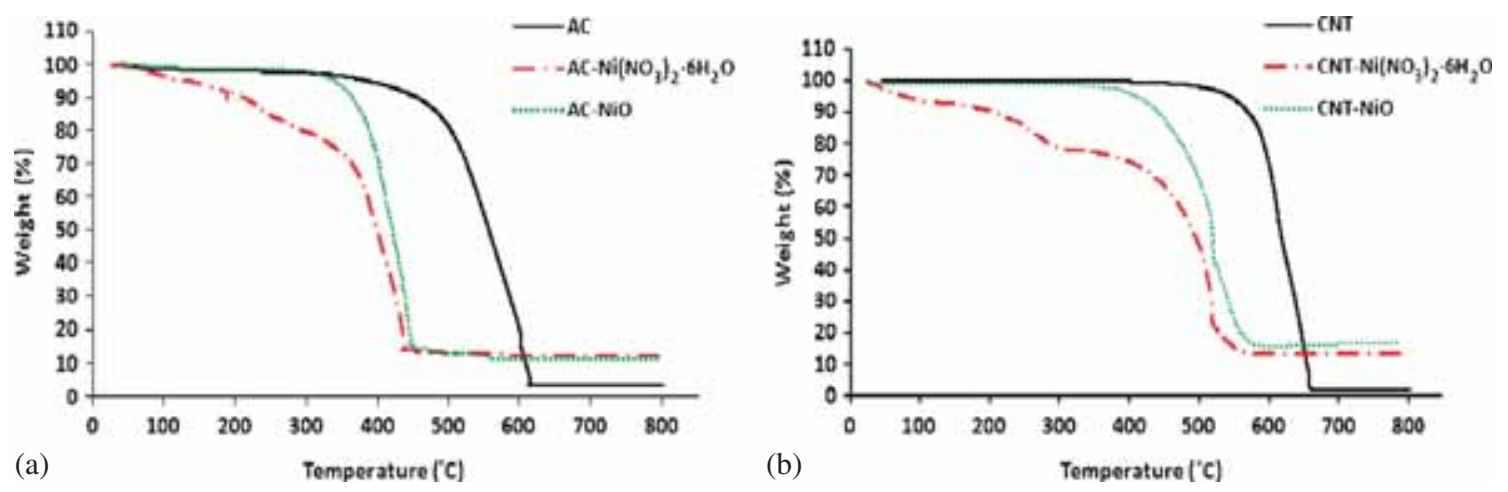

Figure 1. TGA under atmospheric air with a $100 \mathrm{ml} \mathrm{min}^{-1}$ flow rate, before and after $\mathrm{Ni}\left(\mathrm{NO}_{3}\right)_{2}$ calcinations on (a) $\mathrm{AC}$ and (b) CNT.

Table 1. Summary of the TGA results.

\begin{tabular}{|c|c|}
\hline Sample(s) & Description/interpretation of observed behaviour \\
\hline $\mathrm{AC}$ & Oxidation starts at $400^{\circ} \mathrm{C}$ and is complete at $600^{\circ} \mathrm{C}$. \\
\hline CNT & Oxidation starts at $500^{\circ} \mathrm{C}$ and is complete at $650^{\circ} \mathrm{C}$. \\
\hline $\begin{array}{l}\mathrm{AC} \text { and CNT doped with } 10 \% \mathrm{Ni} \\
\text { in the form of } \mathrm{Ni}\left(\mathrm{NO}_{3}\right)_{2} \cdot 6 \mathrm{H}_{2} \mathrm{O}\end{array}$ & $\begin{array}{l}\mathrm{Ni}\left(\mathrm{NO}_{3}\right)_{2} \cdot 6 \mathrm{H}_{2} \mathrm{O} \text { starts decomposing around } 90^{\circ} \mathrm{C} \text {. Around } 200^{\circ} \mathrm{C} \text { an } 11 \% \text { weight } \operatorname{loss}^{\mathrm{a}} \text { is } \\
\text { reached and the decomposition of } \mathrm{Ni}\left(\mathrm{NO}_{3}\right)_{2} \text { to } \mathrm{NiO} \text { starts. The decomposition of } \mathrm{Ni}\left(\mathrm{NO}_{3}\right)_{2} \\
\text { to } \mathrm{NiO} \text { is complete at around } 300^{\circ} \mathrm{C} \text {. }^{\mathrm{b}} \text { The respective oxidations of } \mathrm{AC} \text { and } \mathrm{CNT} \text { start at } \\
380 \text { and } 400^{\circ} \mathrm{C} \text { and end (with an } 87 \% \text { weight loss) at } 420 \text { and } 560^{\circ} \mathrm{C} .^{\mathrm{c}}\end{array}$ \\
\hline $\mathrm{AC} \cdot \mathrm{NiO}$ & Weight loss starts at $380^{\circ} \mathrm{C}$ and ends ( $87 \%$ weight loss) at $420^{\circ} \mathrm{C}^{\mathrm{c}}$ \\
\hline $\mathrm{CNT} \cdot \mathrm{NiO}$ & Weight loss starts at $400^{\circ} \mathrm{C}$ and ends ( $87 \%$ weight loss) at $560^{\circ} \mathrm{C} .^{\mathrm{c}}$ \\
\hline
\end{tabular}

${ }^{a}$ Attributed mainly to the loss of water.

${ }^{\mathrm{b}}$ This result is in line with the finding of Brockner et al [48].

${ }^{\mathrm{c}}$ The oxidation temperatures of $\mathrm{AC}$ and $\mathrm{CNT}$ are lowered upon doping.

(1, 5 and 10\%). The TEM images shown in figure 3 for raw and doped CNT with different nickel oxide percentages were used to characterize the structure of the nanotubes and to observe the distribution of nickel oxide particles on their surfaces. The images show that the nanotubes have many curvature sites. They also show that the nickel oxide nanoparticles on the surface of doped CNT were spherical and varied in diameter from 10 to $60 \mathrm{~nm}$ as shown in Supplementary figure $\mathrm{S} 1$.

The XRD spectra were obtained using an X-ray diffractometer. As figure 4 shows, there is a distinct carbon peak at $25.89^{\circ}$ in three spectra; one for unmodified CNT and two for modified CNT (before and after calcination). Figure 4 also shows that after calcination the characteristics peaks for nickel nitrate disappear and broad distinct peaks characteristic of nickel oxide appear at $2 \theta$ angles of $36.2^{\circ}, 43.2^{\circ}, 62.07^{\circ}$, $74.7^{\circ}$ and $78.7^{\circ}$. The low peak intensity and broadening [39] indicate that the nickel oxide particles in the doped CNT fall in a low nanosize range.

Figure 5 shows the XPS survey spectrum and the single element scan for Ni $2 p$. The survey spectrum confirms the presence of the carbon, oxygen and nickel. The binding energies obtained for $\mathrm{Ni} 2 \mathrm{p}_{1 / 2}$ at $856.0,861.5$ and for $\mathrm{Ni}$
$2 \mathrm{p}_{3 / 2}$ at $873.8,881.8 \mathrm{eV}$ match the reported binding energy values for $\mathrm{NiO}$ in the XPS fitting online library [40]. The small peaks observed at 853.1 and $870.2 \mathrm{eV}$ for $\mathrm{Ni} 2 \mathrm{p}_{1 / 2}$ and $\mathrm{Ni} 2 \mathrm{p}_{3 / 2}$, respectively, match the reported binding energy for $\mathrm{Ni}$ metal. This might be attributed to the formation of trace of $\mathrm{Ni}$ metals in its zero oxidation state through the preparation process.

As shown in figure 6 the raw and modified AC and CNT exhibit type IV and $\mathrm{V} \mathrm{N}_{2}$ adsorption isotherms, respectively, on the basis of the Brunauer, Deming and Teller (BDDT) classification [41]. In all isotherms a hysteresis loop was either absent or too slight to be discerned, which reflects the near absence of a mesoporous structure. Table 3 presents the surface areas (SAs) and the results of micropore analyses for the adsorbents on the basis of BET and $V-t$ methods of analysis respectively. It has been observed that the highest surface area is for ACNI1 and the other AC-based adsorbents follow the order AC $>$ ACNI10 $>$ ACNI5 with a little decrease in the surface area after modification with nickel oxide. However, in case of the CNT-based adsorbents the surface areas follow the trend CNT > CNTNI1 > CNTNI10 > CNTNI5. The same trend was observed in the adsorbents' micropore surface area while the adsorbents' micropore volumes 

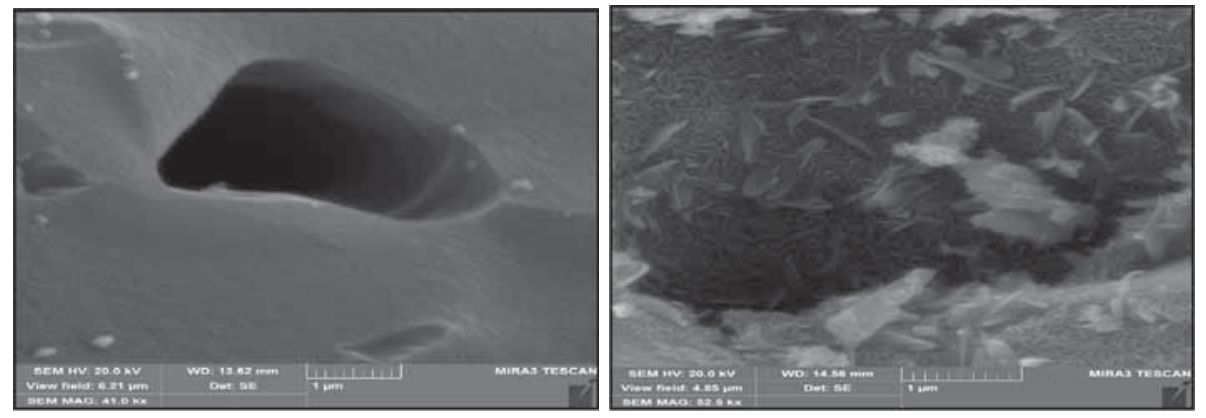

(a)

(b)
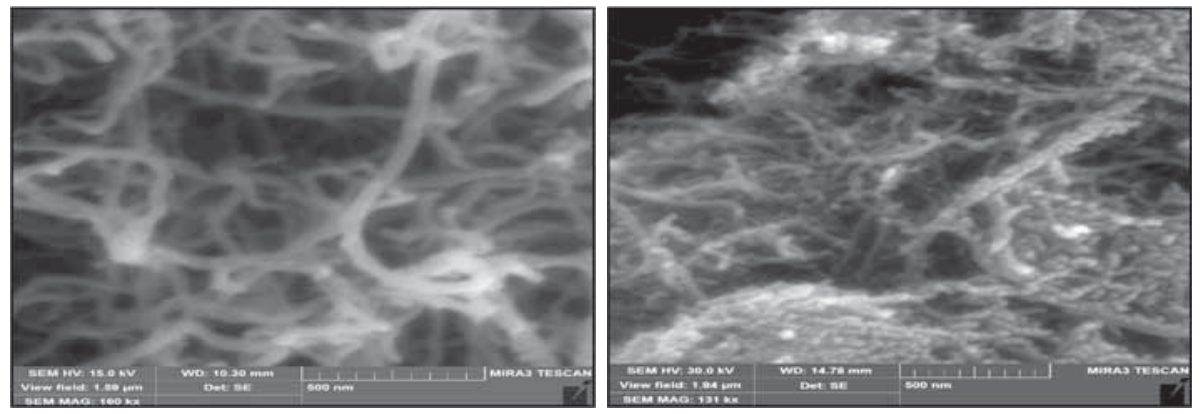

(c)

(d)

Figure 2. SEM photographs for AC (a) before, (b) after and for CNT (c) before and (d) after impregnation with nickel oxide.

Table 2. Weight per cent of nickel in the doped carbon materials adsorbents compared to the theoretical percentage of nickel.

\begin{tabular}{lcr}
\hline Adsorbent & Element & Weight \% \\
\hline \multirow{2}{*}{ AC } & $\mathrm{C}$ & 92.01 \\
\multirow{2}{*}{ ACNI10 } & $\mathrm{O}$ & 7.99 \\
& $\mathrm{C}$ & 75.36 \\
\multirow{2}{*}{ ACNI5 } & $\mathrm{O}$ & 13.36 \\
& $\mathrm{Ni}$ & 11.28 \\
& $\mathrm{C}$ & 79.48 \\
ACNI1 & $\mathrm{O}$ & 15.73 \\
& $\mathrm{Ni}$ & 4.79 \\
& $\mathrm{C}$ & 89.08 \\
CNT & $\mathrm{O}$ & 9.56 \\
& $\mathrm{Ni}$ & 1.36 \\
CNTNI10 & $\mathrm{C}$ & 97.33 \\
& $\mathrm{O}$ & 2.67 \\
& $\mathrm{C}$ & 84.43 \\
CNTNI5 & $\mathrm{O}$ & 5.83 \\
& $\mathrm{Ni}$ & 9.74 \\
& $\mathrm{C}$ & 90.68 \\
CNTNI1 & $\mathrm{O}$ & 4.53 \\
& $\mathrm{Ni}$ & 4.79 \\
& $\mathrm{C}$ & 94.97 \\
& $\mathrm{O}$ & 4.06 \\
& $\mathrm{Ni}$ & 0.97 \\
\hline
\end{tabular}

$(V)$ follow the order $\mathrm{AC}>\mathrm{ACNI} 1>\mathrm{ACNI} 10>\mathrm{ACNI} 5$ $>$ CNTNI1. On the other hand, microporosity has not been observed in CNT, CNTNI10, and CNTNI5. The decrease in the surface areas and micropore volumes of doped $\mathrm{AC}$ and CNT is attributable to the blocking of their pores at high percentages of nickel oxide.

\subsection{Adsorption isotherms of thiophene and DBT}

Figures 7 and 8, respectively, show the Freundlich and Langmuir fits for the adsorption of thiophene and DBT on $\mathrm{AC}$, ACNI10, ACNI5, ACNI1, CNT, CNTNI10, CNTNI5 and CNTNI1. The Langmuir model (equation (1)) assumes a homogeneous adsorbent surface with the same adsorption energy and with no interaction between molecules adsorbed on neighbour sites [42].

$$
q_{\mathrm{e}}=\frac{Q_{\mathrm{max}} b C_{\mathrm{e}}}{1+b C_{\mathrm{e}}} .
$$

Equation (1) can be rearranged to give the following linear form:

$$
\frac{C_{\mathrm{e}}}{q_{\mathrm{e}}}=\frac{1}{b Q_{\max }}+\frac{C_{\mathrm{e}}}{Q_{\max }},
$$

where $q_{\mathrm{e}}\left(\mathrm{mg} \mathrm{g}^{-1}\right)$ is the adsorption capacity at equilibrium, $Q_{\max }\left(\mathrm{mg} \mathrm{g}^{-1}\right)$ the maximum adsorption capacity, $b$ the Langmuir constant, and $C_{\mathrm{e}}\left(\mathrm{mg} \mathrm{l}^{-1}\right)$ the concentration of the sulphur compound in the solution at equilibrium.

The $q_{\mathrm{e}}$ can be calculated using the following equation:

$$
q_{\mathrm{e}}=\frac{V\left(C_{\mathrm{o}}-C_{\mathrm{e}}\right)}{m},
$$

where $V(\mathrm{ml})$ is the volume of solution in the adsorption experiment, $C_{\mathrm{o}}\left(\mathrm{mg} \mathrm{l}^{-1}\right)$ the initial concentration of sulphur compound in the solution, and $m(\mathrm{mg})$ the mass of adsorbent. 

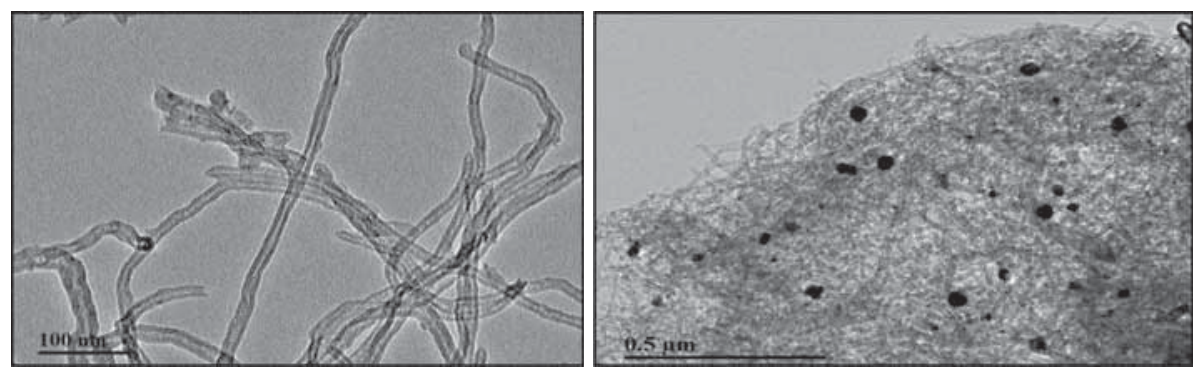

(a)

(b)
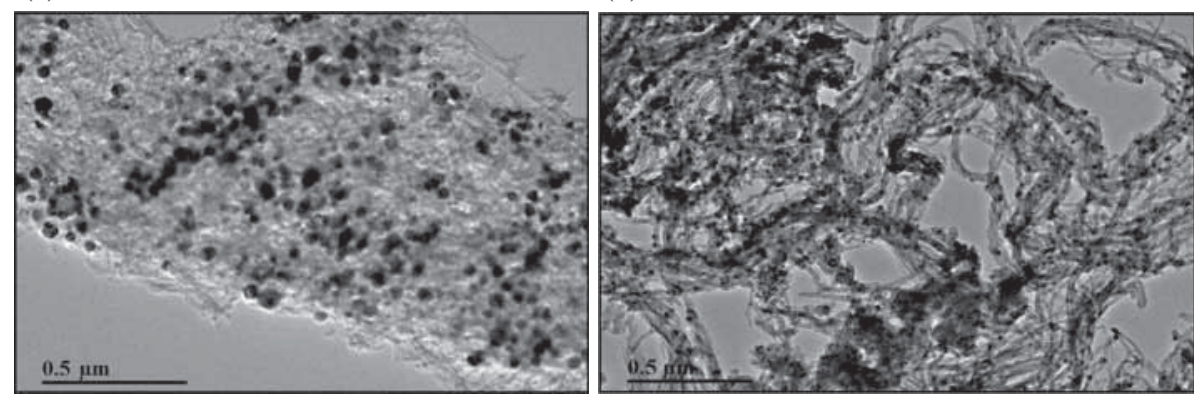

(c)

(d)

Figure 3. FE-TEM image for CNT before impregnation (a) and after impregnation by (b) $1 \%$, (c) $5 \%$ and (d) $10 \%$ nickel oxide nanoparticles.

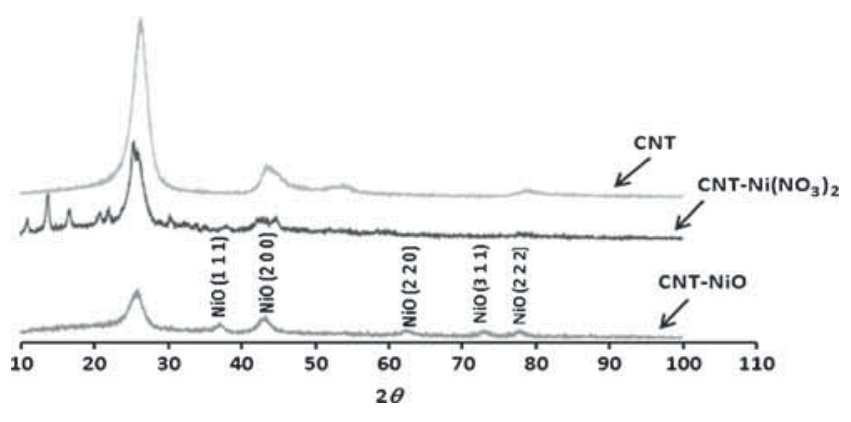

Figure 4. XRD for CNT before and after impregnation.

The Freundlich model (equation (4)) assumes that the adsorption takes place at a heterogeneous adsorbent surface with a multi-layer adsorption capacity [42]

$$
q_{\mathrm{e}}=K_{\mathrm{F}} C_{\mathrm{e}}^{1 / n} \text {. }
$$

The linear form of this equation can be written as

$$
\ln \left(q_{\mathrm{e}}\right)=\ln \left(K_{\mathrm{F}}\right)+\frac{1}{n} \ln \left(C_{\mathrm{e}}\right),
$$

where $q_{\mathrm{e}}\left(\mathrm{mg} \mathrm{g}^{-1}\right)$ is the adsorption capacity at equilibrium, $C_{\mathrm{e}}\left(\mathrm{mg} \mathrm{l}^{-1}\right)$ the concentration of the sulphur compound in the solution at equilibrium, $K_{\mathrm{F}}$ is the Freundlich constant and $n$ is a heterogeneity parameter.

The maximum adsorption capacity $\left(Q_{\max }\right)$ for each adsorbent was obtained from the slope of the linearized Langmuir model (equation (2)). The $n$-value for each adsorbent was obtained from the slope of the linear least square fit of $\ln \left(q_{\mathrm{e}}\right) v s \cdot \ln \left(C_{\mathrm{e}}\right)$ (equation (5)) while the intercept was used to calculate the Freundlich constant $\left(K_{\mathrm{F}}\right)$. The uncertainties in the parameters of the Langmuir and Freundlich isotherms and of pseudo-second-order kinetics were calculated using the uncertainties in the slopes and intercepts of the corresponding linear least-squares fits. Each parameter was calculated three times; using the relevant slope (or intercept) and its minimum and maximum values. The standard deviation calculated from those three values was taken as an estimate of the uncertainty in the parameter calculated from the slope (or intercept). $n$ and $K_{\mathrm{F}}$ values give an idea about the degree of surface heterogeneity and the adsorption capacity, respectively. Larger $n$ and $K_{\mathrm{F}}$ values correspond, respectively, to greater adsorbent surface heterogeneity and higher adsorption capacity [43]. As shown in table 4, the $n$ and $K_{\mathrm{F}}$ values for thiophene adsorption on modified adsorbents with nickel oxide nanoparticles are larger than those of unmodified carbon adsorbents, indicating that the modification increases the adsorbent's surface heterogeneity and adsorption capacity for thiophene. $K_{\mathrm{F}}$ values increased for modified adsorbents reflecting a higher adsorption capacity for thiophene molecules on them relative to unmodified adsorbents. However, the $n$ and $K_{\mathrm{F}}$ values for DBT on unmodified and modified adsorbents did not differ appreciably but were higher than those for thiophene, which indicates that DBT has a better tendency for adsorption and in turn a higher adsorption capacity.

For the adsorption of DBT the Freundlich fits had comparable or slightly higher squares of correlation coefficients than the Langmuir fits. This consistency with both models reflects the complexity and non-uniformity of the adsorbents' and the predominance of multilayer adsorption. For thiophene only the Freundlich model fitted the adsorption results well possibly due to the weaker interaction of thiophene, relative to DBT, with the adsorbents. 

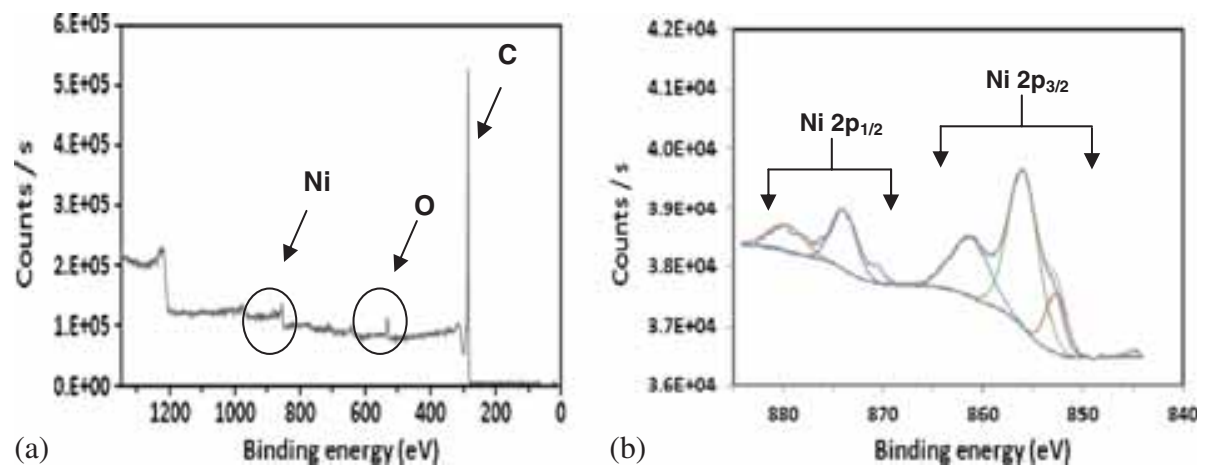

Figure 5. (a) XPS survey spectra of CNTNI10 (b) Ni 2p high-resolution XPS spectra of CNTNI10.
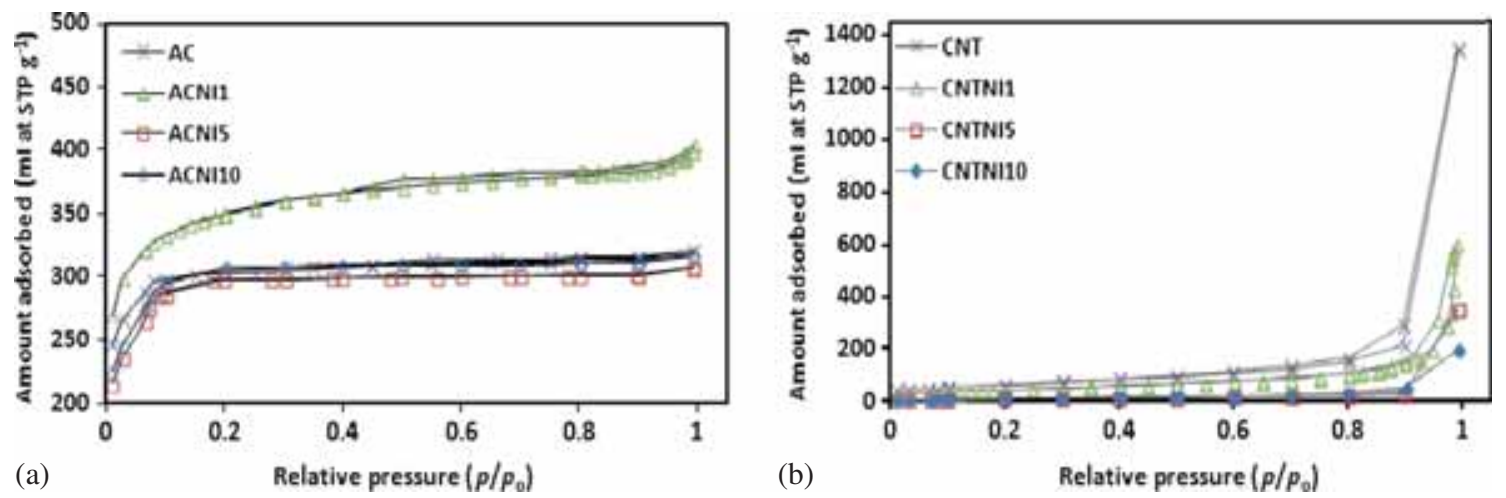

Figure 6. The $\mathrm{N}_{2}$ adsorption isotherm at $77 \mathrm{~K}$ on unmodified and modified (a) AC and (b) CNT with nickel oxide.

Table 3. Surface area, micropore surface area, volume and surface $\mathrm{pH}$ of $\mathrm{AC}$ and $\mathrm{CNT}$ at different loadings of nickel oxide.

\begin{tabular}{lcrlcc}
\hline & \multicolumn{2}{c}{ BET } & & \multicolumn{2}{c}{$V-t$ method } \\
\cline { 2 - 3 } \cline { 5 - 6 } Adsorbent & $\mathrm{pH}$ & $\begin{array}{c}\text { SA } \\
\left(\mathrm{m}^{2} \mathrm{~g}^{-1}\right)\end{array}$ & & $\begin{array}{c}\text { Micropore volume } \\
\left(\mathrm{ml} \mathrm{g}^{-1}\right)\end{array}$ & $\begin{array}{c}\text { Micropore SA } \\
\left(\mathrm{m}^{2} \mathrm{~g}^{-1}\right)\end{array}$ \\
\hline AC & 9.35 & 882 & & 0.466 & 865 \\
ACNI10 & 8.97 & 825 & & 0.379 & 792 \\
ACNI5 & 8.21 & 745 & & 0.377 & 699 \\
ACNI1 & 8.44 & 1080 & & 0.384 & 921 \\
CNT & 5.81 & 217 & & - & 195 \\
CNTN10 & 5.68 & 118 & & - & 99 \\
CNTN5 & 5.75 & 90 & & - & 69 \\
CNTN1 & 5.58 & 162 & & 0.011 & 134 \\
\hline
\end{tabular}

The highest adsorption capacity (74 $\pm 5 \mathrm{mg} \mathrm{g}^{-1}$ ) was for ACNI5 and the others follow the trend ACNI1 > ACNI10 > AC $>$ CNTNI $5>$ CNTNI $1>$ CNTNI10 $>$ CNT. Except for ACNI1 impregnation of AC and CNT with nickel oxide generally reduced their surface area and pore volume. Probably the absence of agglomeration of the nickel oxide in ACNI1 and in turn the absence of blocking of pores led to an increase in its surface area. The increase in the overall adsorption of DBT on modified AC and CNT relative to unmodified AC and CNT is in the main attributable to the active nickel oxide sites. The main contribution of carbon materials used in the adsorption process is in enhancing direct adsorption of thiophene and DBT compounds through $\pi-\pi$ and van der Waals interactions with the surface of unmodified carbon materials. Furthermore, their large surface area assist in improving the dispersion of nickel oxide nanoparticles, which in turn increase the uncovered active nickel oxide sites on the modified carbon materials. The acidic nature of unsaturated surface of nickel oxide makes it play a major role in improving the adsorption of DBT (Lewis base) through the acid-base interaction through direct sulphur metal bond or $\pi$-complexation between $\mathrm{Ni}^{2+}$ and thiophenic aromatic rings [13,25].

As depicted in figure 9, the maximum enhancement in the $\mathrm{AC}$ and CNT adsorption capacities was after modification with $5 \%$ percentage loading of nickel oxide. The $Q_{\max }$ of unmodified AC adsorbent for DBT was enhanced by about $78 \%$ after the modification with $5 \%$ nickel loading percentage. While the enhancement in $Q_{\max }$ of unmodified CNT was approximately $62 \%$ after the modification with $5 \%$ nickel oxide nanoparticles. The slight improvement in the adsorption capacities AC and CNT modified with $10 \%$ nickel oxide may be attributed to the agglomeration of the nanoparticles, which in turn led to a decrease in the active adsorption sites on the adsorbents' surface. Consequently, the significant increase in the adsorption of DBT from model diesel using carbon adsorbents doped with 5\% $\mathrm{NiO}$ nanoparticles 

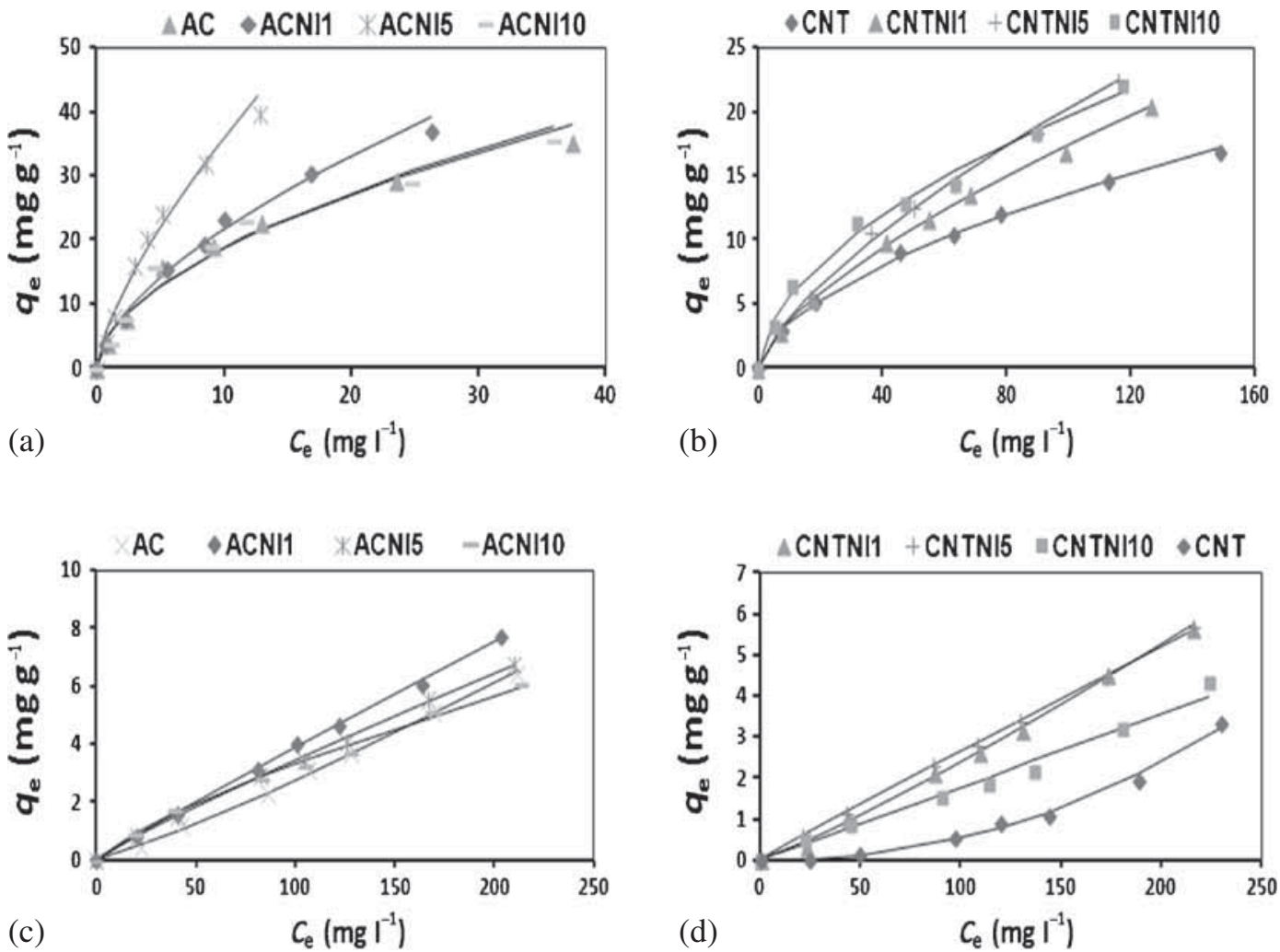

Figure 7. Adsorption isotherms of (a) DBT on AC, ACNI1, ACNI5 and ACNI10, (b) DBT on CNT, CNTNI1, CNTNI5 and CNTNI10, (c) thiophene on AC, ACNI1, ACNI5 and ACNI10 and (d) thiophene on CNT, CNTNI1, CNTNI5 and CNTNI10 at $25^{\circ} \mathrm{C}$. The solid lines are fits to the Freundlich model.
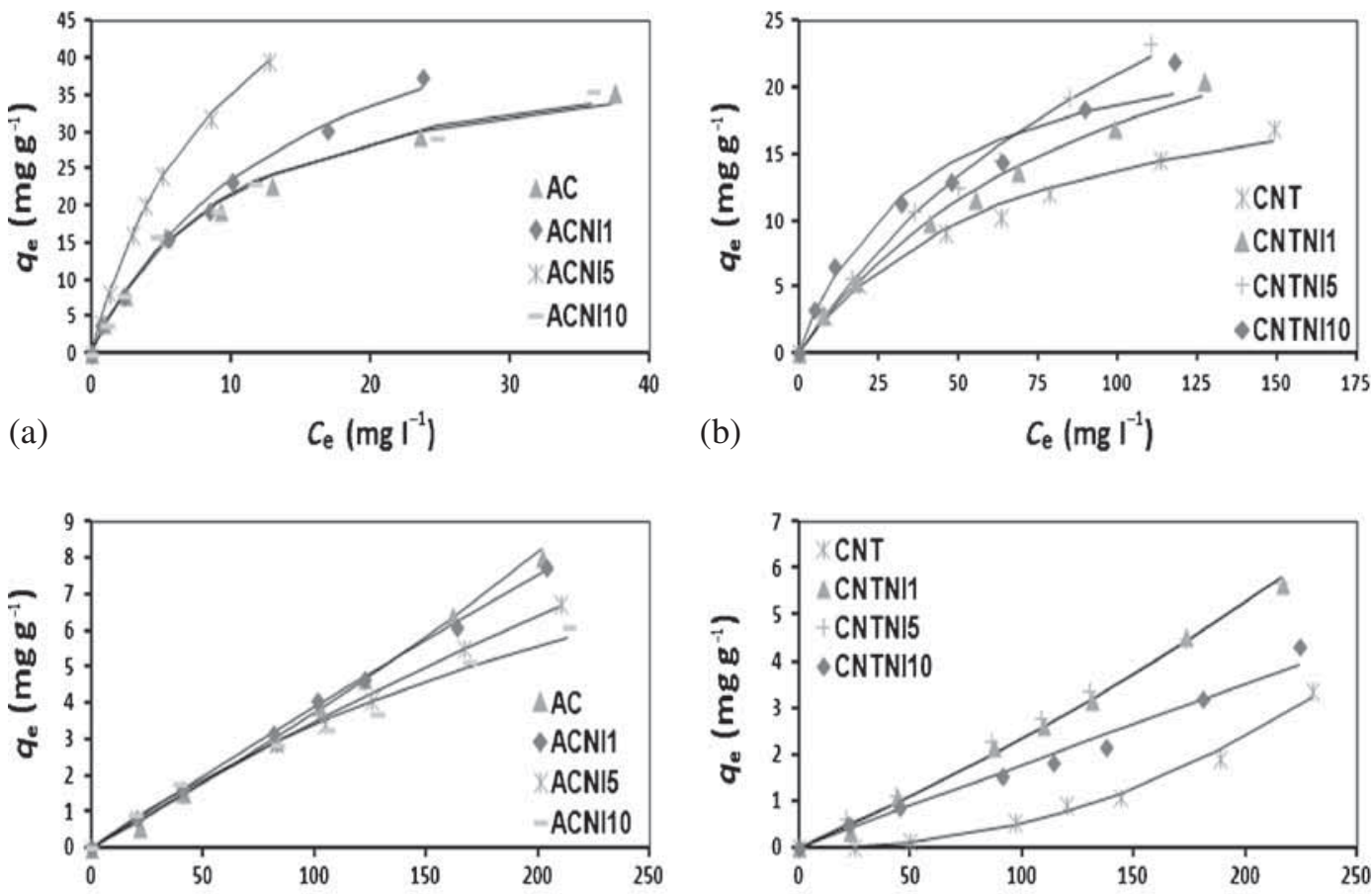

(c)

$C_{\mathrm{e}}\left(\mathrm{mg} \mathrm{I}^{-1}\right)$

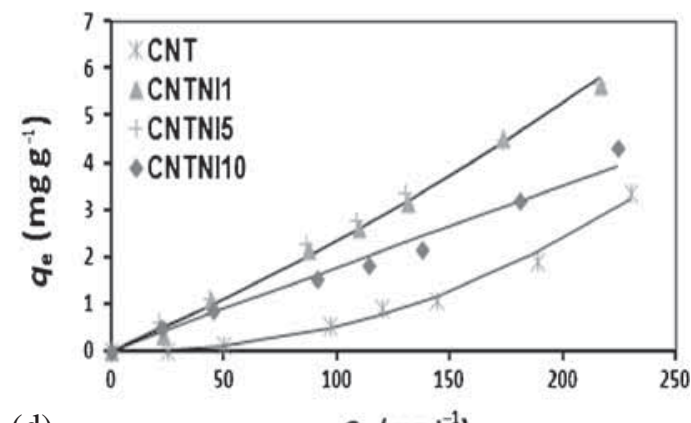

(d)

$C_{e}\left(\mathrm{mg} \mathrm{I}^{-1}\right)$

Figure 8. Adsorption isotherms of (a) DBT on AC, ACNI1, ACNI5 and ACNI10, (b) DBT on CNT, CNTNI1, CNTNI5 and CNTNI10, (c) thiophene on AC, ACNI1, ACNI5 and ACNI10 and (d) thiophene on CNT, CNTNI1, CNTNI5 and CNTNI10 at $25^{\circ} \mathrm{C}$. The solid lines are fits to the Langmuir model. 
Table 4. Freundlich and Langmuir parameters and correlation coefficient for thiophene and DBT adsorption on pristine CNT and CNT impregnated with nickel oxide. The calculation of uncertainty estimates is described in the text. Uncertainties are not given where the values of the correlation coefficients are prohibitive.

\begin{tabular}{|c|c|c|c|c|c|c|}
\hline \multirow[b]{3}{*}{ Adsorbent } & \multicolumn{6}{|c|}{ Freundlich } \\
\hline & \multicolumn{3}{|c|}{ Thiophene } & \multicolumn{3}{|c|}{ DBT } \\
\hline & $n$ & $K_{\mathrm{F}}\left(\mathrm{mg}^{(1-1 / n)} \mathrm{mg}^{-1} 1^{1 / n}\right)$ & $R^{2}$ & $n$ & $K_{\mathrm{F}}\left(\mathrm{mg}^{(1-1 / n)} \mathrm{mg}^{-1} 1^{1 / n}\right)$ & $R^{2}$ \\
\hline$\overline{\mathrm{AC}}$ & $0.83 \pm 0.04$ & $(1.1 \pm 04) \times 10^{-2}$ & 0.9898 & $1.7 \pm 0.1$ & $4.9 \pm 0.5$ & 0.9747 \\
\hline CNT & $0.45 \pm 0.02$ & $(2.0 \pm 0.8) \times 10^{-5}$ & 0.9934 & $1.69 \pm 0.04$ & $(8.9 \pm 0.5) \times 10^{-1}$ & 0.9968 \\
\hline ACNI10 & $1.30 \pm 0.06$ & $(10 \pm 1) \times 10^{-2}$ & 0.9897 & $1.7 \pm 0.2$ & $4.8 \pm 0.7$ & 0.9480 \\
\hline ACNI5 & $1.12 \pm 0.02$ & $(5.6 \pm 0.3) \times 10^{-2}$ & 0.9989 & $1.29 \pm 0.09$ & $6.4 \pm 0.5$ & 0.9782 \\
\hline ACNI1 & $1.02 \pm 0.01$ & $(4.3 \pm 0.3) \times 10^{-2}$ & 0.9991 & $1.59 \pm 0.05$ & $5.2 \pm 0.2$ & 0.9948 \\
\hline CNTNI10 & $1.12 \pm 0.06$ & $(3.0 \pm 0.7) \times 10^{-2}$ & 0.9856 & $1.80 \pm 0.09$ & $1.5 \pm 0.2$ & 0.9880 \\
\hline CNTNI5 & $1.03 \pm 0.02$ & $(3.0 \pm 0.2) \times 10^{-2}$ & 0.9986 & $1.39 \pm 0.03$ & $(7.5 \pm 0.5) \times 10^{-1}$ & 0.9976 \\
\hline \multirow[t]{4}{*}{ CNTNI1 } & $0.88 \pm 0.04$ & $(1.3 \pm 0.3) \times 10^{-2}$ & 0.9908 & $1.45 \pm 0.02$ & $(7.4 \pm 0.3) \times 10^{-1}$ & 0.9992 \\
\hline & \multicolumn{6}{|c|}{ Langmuir } \\
\hline & \multicolumn{3}{|c|}{ Thiophene } & \multicolumn{3}{|c|}{ DBT } \\
\hline & $Q_{\max }\left(\mathrm{mg} \mathrm{g}^{-1}\right)$ & $b\left(\mathrm{dm}^{3} \mathrm{mg}^{-1}\right)$ & $R^{2}$ & $Q_{\max }\left(\mathrm{mg} \mathrm{g}^{-1}\right)$ & $b\left(\mathrm{dm}^{3} \mathrm{mg}^{-1}\right)$ & $R^{2}$ \\
\hline $\mathrm{AC}$ & - & - & 0.4657 & $42 \pm 3$ & $(1.1 \pm 0.1) \times 10^{-1}$ & 0.9795 \\
\hline $\mathrm{CNT}$ & - & - & 0.6969 & $24 \pm 2$ & $(1.5 \pm 0.1) \times 10^{-2}$ & 0.9702 \\
\hline ACNI10 & $14 \pm 3$ & $(3.4 \pm 0.4) \times 10^{-3}$ & 0.8110 & $48 \pm 3$ & $(8.2 \pm 0.2) \times 10^{-2}$ & 0.9850 \\
\hline ACNI5 & $31 \pm 7$ & $(1.3 \pm 0.2) \times 10^{-3}$ & 0.8208 & $74 \pm 5$ & $(9.4 \pm 0.3) \times 10^{-2}$ & 0.9793 \\
\hline ACNI1 & - & - & 0.4975 & $53 \pm 5$ & $(8.4 \pm 0.1) \times 10^{-2}$ & 0.9556 \\
\hline CNTNI10 & - & - & 0.1792 & $28 \pm 3$ & $(2.3 \pm 0.1) \times 10^{-2}$ & 0.9337 \\
\hline CNTNI5 & - & - & 0.1287 & $39 \pm 4$ & $(1.05 \pm 0.03) \times 10^{-2}$ & 0.9616 \\
\hline CNTNI1 & - & - & 0.4191 & $34 \pm 3$ & $(1.07 \pm 0.03) \times 10^{-2}$ & 0.9542 \\
\hline
\end{tabular}

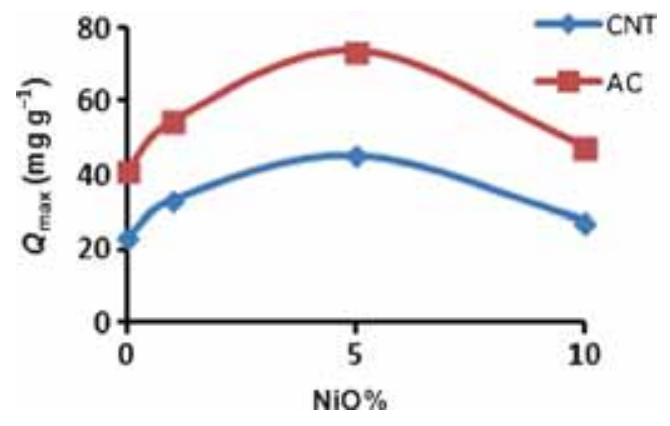

Figure 9. Effect of nickel oxide loading on the adsorption capacities of AC and CNT.

is a consequence of generating more active adsorption sites on the surface of carbon rather than an increase in the surface area and in the pore volume compared to those carbon materials modified with other $\mathrm{NiO}$ percentages (1 and 10\%).

\subsection{DBT adsorption kinetics}

Studying adsorption kinetics in batch mode is essential to the design of adsorption columns for further study and for industrial applications [6]. The results presented in figure 10 show that for all adsorbents the adsorption-desorption equilibrium for both thiophene and DBT is reached within $1 \mathrm{~h}$ and no significant change in the adsorption capacities was observed after that time. Fast adsorption of thiophene and DBT was observed in the first 20 min of contact time due to the maximum availability of unoccupied active sites on the adsorbents. The adsorption kinetic data for DBT and thiophene on the prepared adsorbents were fitted using the most frequently used kinetic models reported by Lagergren [44] and Ho [45] that led to a pseudo-first-order adsorption rate

$$
\ln \left(q_{\mathrm{e}}-q_{\mathrm{t}}\right)=\ln \left(q_{\mathrm{e}}\right)-k_{1} t
$$

and a pseudo-second-order adsorption rate

$$
\frac{t}{q_{\mathrm{t}}}=\frac{1}{q_{\mathrm{e}}^{2} k_{2}}+\frac{1}{q_{\mathrm{e}}},
$$

respectively, where $q_{\mathrm{e}}\left(\mathrm{mg} \mathrm{g}^{-1}\right)$ is the adsorption capacity at equilibrium, $q_{\mathrm{t}}$ in $\left(\mathrm{mg} \mathrm{g}^{-1}\right)$ is the adsorption capacity at a time $t$ ( $\min ), k_{1}\left(\mathrm{~min}^{-1}\right)$ is the pseudo-first-order rate constant, and $k_{2}\left(\mathrm{~g} \mathrm{mg}^{-1} \mathrm{~min}^{-1}\right)$ is the pseudo-second-order rate constant. The low correlation coefficients and the large difference between the calculated and experimental values of $q_{\mathrm{e}}$ given in table 5 show the DBT and thiophene data do not fit the pseudo-first-order kinetic model. The correlation coefficients close to or equal to 1 obtained for fits of $t / q_{\mathrm{t}} v s$. $t$ and the closeness of the calculated and experimental values of $q_{\mathrm{e}}$ given in table 6 show the DBT and thiophene data fit the pseudo-second-order kinetic model. The uncertainties in the parameters of the pseudo-second order were calculated on the basis of the uncertainties in the slope and the intercept of the linear $t / q_{\mathrm{t}} v s . t$ plot.

The mechanism of adsorption can be explored by studying the adsorption kinetics. Bearing in mind that the kinetic results fit perfectly into the pseudo-second-order kinetic 

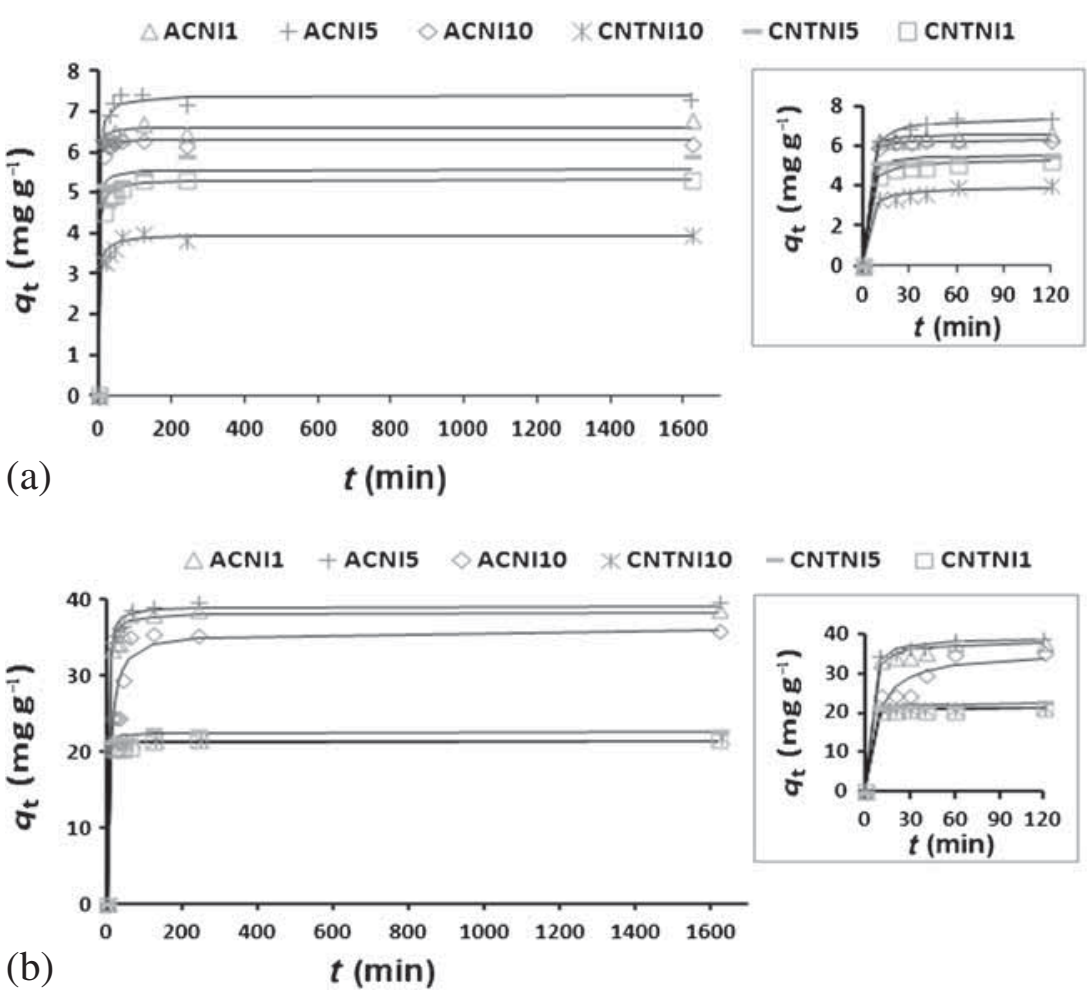

Figure 10. Effect of contact time on the adsorption capacity $\left(q_{\mathrm{t}}\right)$ of AC and CNT with different nickel oxide loading percentages for (a) thiophene and (b) DBT at $25^{\circ} \mathrm{C}$. The solid lines are the predicted $q_{\mathrm{t}}$ values according to pseudo-second-order kinetics. The insets show the onset of a plateau after about $2 \mathrm{~h}$.

Table 5. Pseudo-first-order parameters for thiophene and DBT adsorption on AC and CNT doped with nickel oxide.

\begin{tabular}{|c|c|c|c|c|c|c|c|c|}
\hline \multirow[b]{3}{*}{ Adsorbent } & \multicolumn{8}{|c|}{ Pseudo-first-order parameters } \\
\hline & \multicolumn{4}{|c|}{ Thiophene } & \multicolumn{4}{|c|}{ DBT } \\
\hline & $q_{\mathrm{e}} \exp$ & $q_{\mathrm{e} \text { pred }}$ & $k_{1}\left(\min ^{-1}\right)$ & $R^{2}$ & $q_{\mathrm{e}} \exp$ & $q_{\text {e pred }}$ & $k_{1}\left(\min ^{-1}\right)$ & $R^{2}$ \\
\hline ACNI1 & 6.33 & 0.43 & $8.70 \times 10^{-3}$ & 0.4504 & 35.67 & 21.37 & $8.06 \times 10^{-2}$ & 0.7647 \\
\hline CNTNI1 & 4.02 & 0.90 & $2.39 \times 10^{-2}$ & 0.9373 & 20.63 & 0.86 & $4.00 \times 10^{-4}$ & 0.0045 \\
\hline ACNI5 & 7.43 & 2.60 & $5.92 \times 10^{-2}$ & 0.8825 & 38.95 & 10.34 & $5.07 \times 10^{-2}$ & 0.8589 \\
\hline CNTNI5 & 5.50 & 2.47 & $6.3 \times 10^{-3}$ & 0.3875 & 23.00 & 1.61 & $4.10 \times 10^{-3}$ & 0.3168 \\
\hline ACNI10 & 6.72 & 0.56 & $5.06 \times 10^{-2}$ & 0.9001 & 38.07 & 38.92 & $6.22 \times 10^{-2}$ & 0.7882 \\
\hline CNTNI10 & 5.32 & 1.53 & $4.54 \times 10^{-3}$ & 0.8526 & 21.38 & 0.23 & $8.30 \times 10^{-3}$ & 0.0959 \\
\hline
\end{tabular}

Table 6. Pseudo-second-order parameters for thiophene and DBT adsorption on AC and CNT doped with nickel oxide. The calculation of uncertainty estimates is described in the text.

\begin{tabular}{|c|c|c|c|c|c|c|c|c|}
\hline \multirow[b]{3}{*}{ Adsorbent } & \multicolumn{7}{|c|}{ Pseudo-second-order parameters } & \\
\hline & \multicolumn{4}{|c|}{ Thiophene } & \multicolumn{4}{|c|}{ DBT } \\
\hline & $q_{\mathrm{e} \exp }$ & $q_{\mathrm{e} \text { pred }}$ & $k_{2}\left(\mathrm{~g} \mathrm{mg}^{-1} \mathrm{~min}^{-1}\right)$ & $R^{2}$ & $q_{\mathrm{e} \exp }$ & $q_{\text {e pred }}$ & $k_{2}\left(\mathrm{~g} \mathrm{mg}^{-1} \mathrm{~min}^{-1}\right)$ & $R^{2}$ \\
\hline ACNI10 & 6.33 & $6.38 \pm 0.01$ & $(2.3 \pm 0.4) \times 10^{-1}$ & 1.0000 & 35.7 & $39 \pm 2$ & $(2.5 \pm 0.5) \times 10^{-3}$ & 0.9884 \\
\hline CNTNI10 & 4.02 & $4.16 \pm 0.07$ & $(0.6 \pm 0.1) \times 10^{-1}$ & 0.9989 & 20.6 & $21.5 \pm 0.1$ & $(2.2 \pm 0.1) \times 10^{-1}$ & 1.0000 \\
\hline ACNI5 & 7.43 & $7.63 \pm 0.09$ & $(0.5 \pm 0.1) \times 10^{-1}$ & 0.9994 & 39.0 & $39.7 \pm 0.4$ & $(1.1 \pm 0.2) \times 10^{-2}$ & 0.9997 \\
\hline CNTNI5 & 5.50 & $5.56 \pm 0.08$ & $(1.0 \pm 0.3) \times 10^{-1}$ & 0.9993 & 23.0 & $23.2 \pm 0.4$ & $(2.7 \pm 0.1) \times 10^{-2}$ & 0.9989 \\
\hline ACNI1 & 6.72 & $6.77 \pm 0.07$ & $(1.1 \pm 0.4) \times 10^{-1}$ & 0.9995 & 38.1 & $39.0 \pm 0.5$ & $(1.0 \pm 0.3) \times 10^{-2}$ & 0.9993 \\
\hline CNTNI1 & 5.32 & $5.42 \pm 0.05$ & $(0.7 \pm 0.1) \times 10^{-1}$ & 0.9996 & 21.4 & $21.5 \pm 0.2$ & $(4.6 \pm 0.2) \times 10^{-2}$ & 0.9995 \\
\hline
\end{tabular}


model for DBT and thiophene using all adsorbents, the influence of mass transfer resistance on binding DBT (or thiophene) on adsorbents was verified using the intra-particle diffusion model represented as [46].

$$
q_{\mathrm{t}}=k_{\mathrm{id}} t^{0.5}+C
$$

where $k_{\mathrm{id}}$ is the intra-particle diffusion rate constant $(\mathrm{mg}$ $\mathrm{g}^{-1} \min ^{0.5}$ ), and $C$ a constant related to the thickness of the boundary layer $\left(\mathrm{mg} \mathrm{g}^{-1}\right)$. Thus, the diffusion constant $k_{\text {id }}$ can be obtained from the slope of the plot of $q_{\mathrm{t}} v s$. the square root of time. If this plot passes through the origin, then intra-particle diffusion is the sole rate controlling step.

Figure 11 shows plots of $q_{\mathrm{t}} v s . t^{0.5}$ for DBT on ACNI10, ACNI5 and ACNI1. The linear parts in these plots imply that the adsorption processes involve two kinetic stages or sorption rates [46]. The first linear part may be attributed to intra-particle diffusion, which produced a delay in the adsorption process. The second stage may be attributed to diffusion through micropores. Table 7 shows the calculated values of the diffusion constants.

\subsection{Adsorbents' loading effect}

As shown in figure 12, the percentage removal of DBT and thiophene increased with the increase in the dose of AC doped with nickel oxide. At an absorbent dosage of $250 \mathrm{mg}$ the per cent removal of DBT was much higher for ACNI5 (around 97.5\%) than for AC (90.4\%); these percentages reached their highest values 99.6 and $96.1 \%$, respectively, at a $750 \mathrm{mg}$ loading. The removal efficiencies for thiophene were much lower but followed the same trend. Only $34.3 \%$ removal of thiophene was achieved when $750 \mathrm{mg}$ of ACNI5 was used, while $32.1 \%$ removal was achieved with AC. On using CNTNI5 and CNT at a dosage of $250 \mathrm{mg}$
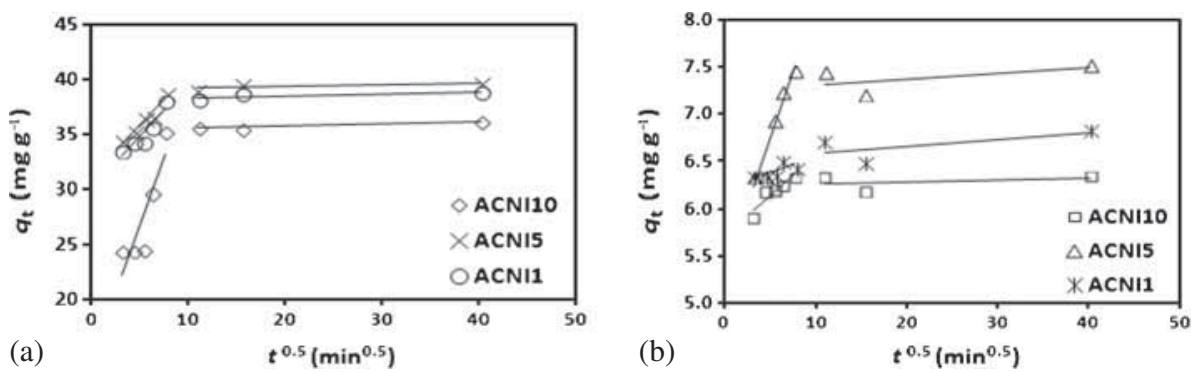

Figure 11. Results of the intra-particle diffusion model for (a) DBT adsorption and (b) thiophene adsorption on ACNI10, ACNI5 and ACNI1.

Table 7. Intra-particle diffusion parameters.

\begin{tabular}{|c|c|c|c|c|c|c|}
\hline \multirow[b]{3}{*}{ Adsorbents } & \multicolumn{6}{|c|}{ Intra-particle diffusion parameters } \\
\hline & \multicolumn{3}{|c|}{ DBT } & \multicolumn{3}{|c|}{ Thiophene } \\
\hline & $\begin{array}{c}K_{\mathrm{id}}\left(\mathrm{mg} \mathrm{g}^{-1}\right. \\
\left.\min ^{0.5}\right)\end{array}$ & $\begin{array}{c}C \\
\left(\mathrm{mg} \mathrm{g}^{-1}\right)\end{array}$ & $R^{2}$ & $\begin{array}{c}K_{\mathrm{id}}\left(\mathrm{mg} \mathrm{g}^{-1}\right. \\
\left.\min ^{0.5}\right)\end{array}$ & $\begin{array}{c}C \\
\left(\mathrm{mg} \mathrm{g}^{-1}\right)\end{array}$ & $R^{2}$ \\
\hline ACNI10 & 2.40 & 14.62 & 0.7789 & 0.08 & 5.73 & 0.8551 \\
\hline ACNI5 & 0.90 & 31.34 & 0.9553 & 0.28 & 5.34 & 0.9041 \\
\hline ACNI1 & 0.94 & 30.01 & 0.8634 & 0.03 & 6.22 & 0.5359 \\
\hline
\end{tabular}
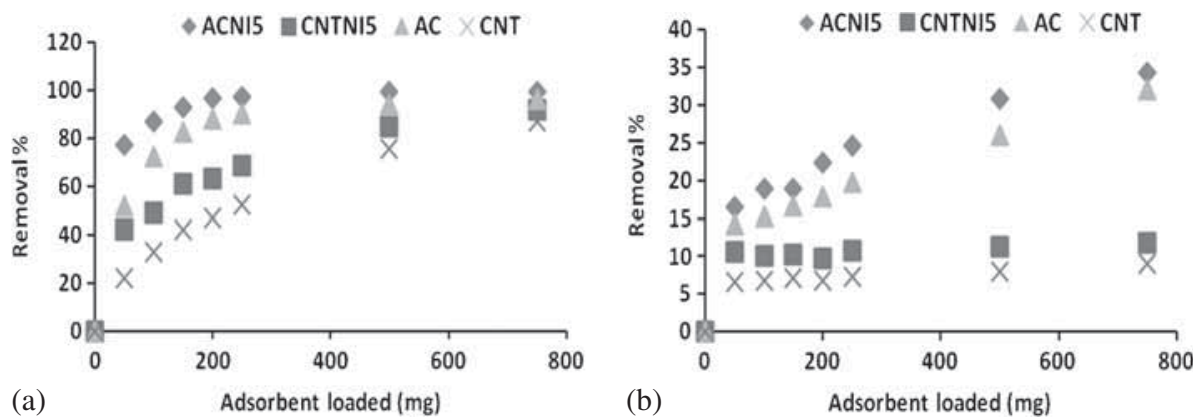

Figure 12. Effect of adsorbent loading on the removal efficiency of (a) dibenzothiophene (DBT) and (b) thiophene, on AC and CNT before and after impregnation with 5\% of nickel oxide at $25^{\circ} \mathrm{C}$. 
68.7 and $52.1 \%$ of DBT and 11.8 and $9.0 \%$ of thiophene were removed, respectively. The low removal of thiophene is attributable to their weaker interaction with the adsorbent sites. The high removal efficiency and good adsorption capacities of DBT by ACNI5 and CNTNI5 led us to study their selectivity which is covered in the next section.

\subsection{Selectivity}

The distribution coefficient $K_{\mathrm{d}}\left(\mathrm{g} \mathrm{g}^{-1}\right)$ was calculated for each analyte based on the following equation:

$$
K_{\mathrm{d}}=\frac{Q_{\mathrm{e}}}{C_{\mathrm{e}}},
$$

where $Q_{\mathrm{e}}$ is the adsorption capacity $\left(\mathrm{mg} \mathrm{g}^{-1}\right)$ and $C_{\mathrm{e}}$ is the sulphur compound or naphthalene equilibrium concentration $\left(\mathrm{mg} \mathrm{l}^{-1}\right)$. The distribution coefficient is used to calculate the selectivity factor for DBT with respect to thiophene and to naphthalene according to the following equation:

$$
k=\frac{K_{\mathrm{d}(\mathrm{DBT})}}{K_{\mathrm{d}(\mathrm{c})}},
$$

where $k$ is the selectivity factor and the subscript $\mathrm{c}$ refers to the competitor molecule (thiopene or naphthalene).

As shown in table 8, the adsorption capacities for DBT on ACNI5 and CNTNI5 are about 41 and $28 \mathrm{mg} \mathrm{g}^{-1}$, respectively. The removal efficiencies for DBT using these adsorbents were 76.4 and $43.4 \%$, respectively, which are about four times the removal efficiencies for naphthalene (22.1 and $9.6 \%)$. However, the selectivity factor of DBT to naphthalene was about 12 for ACNI5 and 6 for CNTNI5. On the other hand, the higher selectivity factors of DBT to thiophene were about 50 using ACNI5 and about 9 using CNTNI5. The selectivity factors of DBT to thiophene and DBT to naphthalene can be explained by three possible factors. First the size of the DBT molecule may be closer the size of the adsorbent pores which allows them to be better trapped into the adsorbent. The second factor is related to the higher dipole moment, molar mass and aromaticity values for DBT which lead to stronger van der Waals and $\pi-\pi$ interactions with the adsorbents surface. The third factor is the lower basicity of thiophene relative to DBT and in turns its weaker acid-base interaction with nickel oxide (Lewis acid) on the adsorbent surface.

\subsection{Regeneration}

The regeneration of adsorbents was studied because it contributes significantly to their cost effectiveness in diesel desulphurization. The regeneration procedure involved the removal of the DBT adsorbed on ACNI5 and CNTNI5 by heating to $300^{\circ} \mathrm{C}$ for $2 \mathrm{~h}$ in air. The regenerated adsorbents were reused. This adsorption-desorption cycle was repeated five times. As figure 13 shows the adsorption capacity of CNTNI5 remained practically unchanged, while the adsorption capacity of ACNI5\% dropped by about $15 \%$ after the fifth cycle.

\begin{tabular}{|c|c|c|c|c|c|c|c|c|}
\hline \multirow[b]{3}{*}{ Adsorbate } & \multicolumn{8}{|c|}{ Adsorbent } \\
\hline & \multicolumn{4}{|c|}{ ACNI5 } & \multicolumn{4}{|c|}{ CNTNI5 } \\
\hline & $Q_{\max }\left(\mathrm{mg} \mathrm{g}^{-1}\right)$ & $K_{\mathrm{d}}$ & $k_{\mathrm{DBT} / \mathrm{naph} \text { thalene }}$ & $k_{\mathrm{DBT} / \text { thiophene }}$ & $Q_{\max }\left(\mathrm{mg} \mathrm{g}^{-1}\right)$ & $K_{\mathrm{d}}$ & $k_{\mathrm{DBT} / \text { naphthalene }}$ & $k_{\text {DBT/thiophene }}$ \\
\hline DBT & 41.0 & 0.693 & 12.0 & 49.5 & 28.3 & 0.200 & 5.71 & 8.70 \\
\hline Thiophene & 3.50 & 0.014 & & & 5.60 & 0.023 & & \\
\hline Naphthalene & 45.3 & 0.058 & & & 31.6 & 0.035 & & \\
\hline
\end{tabular}

Table 8. Adsorption selectivity of ACNI5 and CNTNI5.
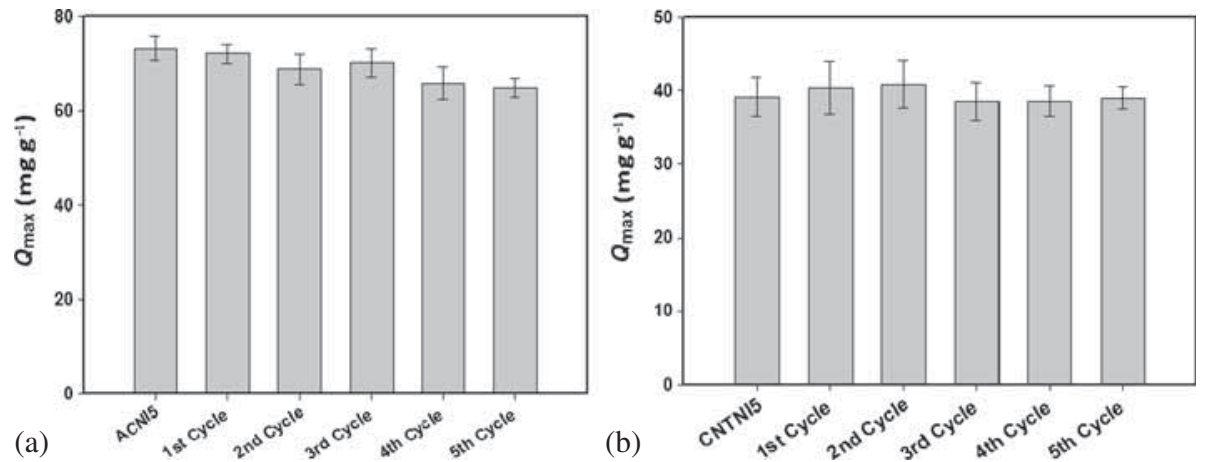

Figure 13. The adsorption capacities for DBT on (a) ACNI5 and (b) CNTNI5 after each of 5 consecutive adsorption-desorption cycles. 


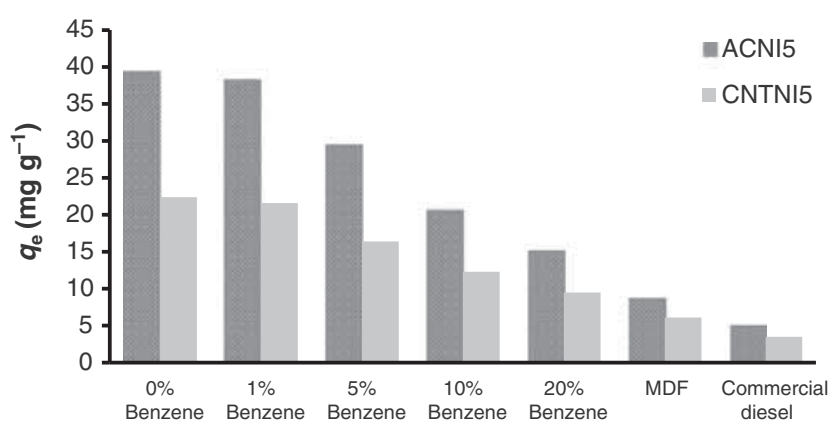

Figure 14. Effect of aromatics on the adsorption capacity for DBT on ACNI5 and CNTNI5.

\subsection{Effect of aromatics}

Diesel fuel consists of complex mixture containing approximately $65 \%$ aliphatic hydrocarbons and $35 \%$ of aromatics hydrocarbons [47]. To study the effect of the aromatic hydrocarbon content on DBT adsorption, the benzene percentage was varied from 0 to $20 \%$ in $n$-hexane. In addition, the adsorption capacities of ACNI5 and CNTNI5 for DBT in another model diesel fuel (MDF), consisting of $25 \% n$ hexane, $45 \% n$-heptane, $10 \%$ benzene, $10 \%$ toluene, $10 \%$ xylene and $1000 \mathrm{mg} \mathrm{l}^{-1}$ naphthalene, were measured. The adsorption capacities of ACNI5 and CNTNI5 for the DBT in a diesel sample purchased from a local Sahel gas station in Dhahran, Saudi Arabia, were also measured. Briefly, $150 \mathrm{mg}$ adsorbents were loaded to aliquots of $25 \mathrm{ml}$ of each of the three preceding solutions and were shaken for $2 \mathrm{~h}$ at a speed of $200 \mathrm{rpm}$. The concentrations of DBT in the MDF and in the benzene/hexane mixtures after adsorption were determined using the HPLC method (described in section 2.5). Prior to its adsorption the concentration of DBT in these mixtures was $250 \mathrm{mg}^{-1}$. The commercial diesel (containing $43.4 \mathrm{mg} \mathrm{DBT}^{-1}$ ) was spiked with DBT to increase its DBT concentration to $243.4 \mathrm{mg} \mathrm{l}^{-1}$ thereby bringing it close to the value of $250 \mathrm{mg} \mathrm{l}^{-1}$ that was used in the model fuel. This concentration dropped to 212.2 and to $221.4 \mathrm{mg}^{-1}$ after adsorption on ACNI5 and CNTNI5, respectively. The DBT concentrations were determined using gas chromatography (Agilent 7890 A) coupled with a sulphur chemiluminescence detector (GC-SCD) (Dual Plasma Technology 355) with hydrophobic Agilent DB-1 GC capillary column $(30 \mathrm{~m} \times 0.32 \mathrm{~mm} \times 1 \mu \mathrm{m})$. As shown in figure 14, the equilibrium adsorption capacities of ACNI5 and CNTNI5 for DBT decreased with the increase in the volume $\%$ of the aromatic hydrocarbon. As expected the lowest adsorption capacities were encountered in the commercial diesel and were 5.2 and $3.7 \mathrm{mg} \mathrm{g}^{-1}$ for ACNI5 and CNTNI5, respectively. This decrease in adsorption capacities is attributable to the severe medium of a commercial diesel that contains other competing aliphatics and aromatics and aromatic sulphur compounds. In addition it may be inferred that the lower adsorption capacities for DBT in the aromatic containing systems is due to an increase in their solvation in these systems.

\section{Conclusion}

Two different types of carbonaceous adsorbents namely AC and CNT doped with three different loadings of nickel oxide (1, 5 and 10\%) were prepared, characterized and tested for the removal of DBT and thiophene from $n$-hexane as model diesel fuel. Introducing nickel oxide on the surface of $\mathrm{AC}$ and CNT shows improvement in their removal efficiency of DBT, this is attributed to acid-base interaction through sulphur metal bond or $\pi$-complexation between nickel oxide and thiophenic aromatic ring. The highest removal efficiency of DBT and thiophene was achieved using ACNI5 adsorbent where the adsorption capacities were 74 and $31 \mathrm{mg} \mathrm{g}^{-1}$ for DBT and thiophene, respectively. The selectivities of ACNI5 and CNTNI5 for DBT relative to thiophene and DBT relative to naphthalene were obtained. The selectivities on ACNI5 for DBT relative to thiophene and DBT relative to naphthalene were 50 and 12, respectively, while the selectivities on CNTNI5 for DBT relative to thiophene and DBT relative to naphthalene were 9 and 6, respectively. These adsorbents showed acceptable reusability after five cycles with practically no loss in the adsorption capacity of CNTNI5 and a maximum of 15\% loss in the adsorption capacity of ACNI5. Three aromatics-containing systems were tested for DBT adsorption. They showed a decrease in adsorption with increase in benzene content. The adsorption capacities obtained in the commercial diesel were 5.2 and $3.7 \mathrm{mg} \mathrm{g}^{-1}$ for ACNI5 and CNTNI5, respectively, which is attributed to the complexity of competing molecules. In general, decrease in adsorption with increase in benzene content may be attributable to greater solvation of DBT.

\section{Acknowledgement}

We acknowledge support for this research by the Chemistry Department and Center for Integrative Petroleum Research (CIPR) in the Research Institute (RI) at King Fahd University of Petroleum \& Minerals (KFUPM).

\section{Electronic Supplementary Material}

Supplementary material pertaining to this article is available on the Bulletin of Materials Science website (www.ias.ac.in/ matersci).

\section{References}

[1] Kim J H, Ma X, Zhou A and Song C 2006 Catal. Today 111 74

[2] E. E. Commission 2009 Directive 2009/30/EC of the European Parliament and of the Council of 23 April 2009 amending Directive 98/70/EC as regards the specification of petrol, diesel and gas-oil and introducing a mechanism to monitor and reduce greenhouse gas emissions and amending Council Directive 1999/32/EC as regards the specification of fuel used by inland waterway vessels and repealing Directive 93/12, EEC (2009) 
[3] Bertelsen B I 2001 Platinum Met. Rev. 4550

[4] Babich I and Moulijn J 2003 Fuel 82607

[5] Song C and Ma X 2003 Appl. Catal. B: Environ. 41207

[6] Ania C O and Bandosz T J 2005 Langmuir 217752

[7] Zhu W, Li H, Jiang X, Yan Y, Lu J and Xia J 2007 Energy Fuels 212514

[8] Cortes-Jácome M, Morales M, Angeles Chavez C, RamírezVerduzco L, López-Salinas E and Toledo-Antonio J 2007 Chem. Mater. 196605

[9] Yu G, Lu S, Chen H and Zhu Z 2005 Carbon 432285

[10] Hoguet J-C, Karagiannakis G P, Valla J A, Agrafiotis C C and Konstandopoulos A G 2009 Int. J. Hydrogen Energy 344953

[11] Matsuzawa S, Tanaka J, Sato S and Ibusuki T 2002 J. Photochem. Photobiol. A: Chem. 149183

[12] Shiraishi Y, Hara H, Hirai T and Komasawa I 1999 Ind. Eng. Chem. Res. 381589

[13] Hernández-Maldonado A J, Qi G and Yang R T 2005 Appl. Catal. B: Environ. 61212

[14] Srivastav A and Srivastava V C 2009 J. Hazard. Mater. 170 1133

[15] Yang R T, Hernández-Maldonado A J and Yang F H 2003 Science $\mathbf{3 0 1} 79$

[16] Wang Y and Yang R T 2007 Langmuir 233825

[17] Alhamed Y A and Bamufleh H S 2009 Fuel 8887

[18] Kumagai S, Ishizawa H and Toida Y 2010 Fuel 89365

[19] Wang Q, Liang X, Qiao W, Liu C, Liu X, Zhan L and Ling L 2009 Fuel Process. Technol. 90381

[20] Wang Q, Liang X, Qiao W, Liu C, Liu X, Zhang R and Ling L 2009 Appl. Surf. Sci. 2553499

[21] Nunthaprechachan T, Pengpanich S and Hunsom M 2013 Chem. Eng. J. 228263

[22] Jayne D, Zhang Y, Haji S and Erkey C 2005 Int. J. Hydrogen Energy 301287

[23] Xiao J, Li Z, Liu B, Xia Q and Yu M 2008 Energy Fuels 22 3858

[24] Khan N A, Hasan Z, Min K S, Paek S-M and Jhung S H 2013 Fuel Process. Technol. 116265

[25] Moosavi E S, Dastgheib S A and Karimzadeh R 2012 Energies 54233

[26] Seredych M and Bandosz T J 2010 Fuel Process. Technol. 91 693
[27] Jeon H-J, Ko C H, Kim S H and Kim J-N 2009 Energy Fuels 232537

[28] Yang Y, Lu H, Ying P, Jiang Z and Li C 2007 Carbon 45 3042

[29] Seredych M and Bandosz T J 2010 Energy Fuels 243352

[30] Safieh K A A, Al-Degs Y S, Sunjuk M S, Saleh A I and Al-Ghouti M A 2015 Environ. Technol. 3698

[31] Shi Y, Liu G, Wang L and Zhang X 2015 Chem. Eng. J. 259 771

[32] Chen H, Zhou X, Shang H, Liu C, Qiu J and Wei F 2004 J. Nat. Gas Chem. 13209

[33] Seredych M, Lison J, Jans U and Bandosz T J 2009 Carbon 472491

[34] Lucas E, Decker S, Khaleel A, Seitz A, Fultz S, Ponce A, Li W, Carnes C and Klabunde K J 2001 Chemistry-A Eur. J. 7 2505

[35] Tanabe K 1981 Catal. Sci. Technol. 2255

[36] Gutiérrez-Alejandre A, Larrubia M A, Ramirez J and Busca G 2006 Vib. Spectrosc. 4142

[37] Lastoskie C, Gubbins K E and Quirke N 1993 J. Phys. Chem. 974786

[38] Lippens B C and De Boer J 1965 J. Catal. 4319

[39] Cullity B 1978 Elements of X-ray! Diffraction (Reading, Massachusetts: Addson-Wesley Publishing Company Inc.)

[40] http://srdata.nist.gov/xps/EnergyTypeValSrch.aspx. Last accessed on September 2015

[41] Brunauer S, Deming L S, Deming W E and Teller E $1940 \mathrm{~J}$. Am. Chem. Soc. 621723

[42] Adamson A W and Gast A P 1997 Phys. Chem. Surf. 6th ed. (New York: John Wiley \& Sons Inc.) p 611

[43] Li L, Quinlivan P A and Knappe D R 2002 Carbon 402085

[44] Lagergren S 1898 Kungliga Svenska Vetenskapsakademiens Handlingar 241

[45] Ho Y and McKay G 1998 Process Saf. Environ. Prot. 76332

[46] Weber W, Asce Jr J M and Morris J C 1963 Proc. Am. Soc. Civil Eng. 8931

[47] Risher J F and Rhodes S W 1995 Toxicological Profile for Fuel Oils (Atlanta, GA: Agency for Toxic Substances and Disease Registry)

[48] Brockner W, Ehrhardt C and Gjikaj M 2007 Thermochim. Acta 45664 